\title{
LA CRITICA DE KANT A DESCARTES (ALGUNAS NOTAS SOBRE EL IDEALISMO TRANSCENDENTAL)
}

Jesús González Fisac

0. En la Critica de la Razón pura Kant examina el «idealismo" de Descartes. Ahora bien, este examen va a resultar al mismo tiempo una "revisión" de la propia doctrina de la $C R p$. el «idealismo transcendental». Se trata de mostrar algunos de los elementos que componen estat revisión.

1. Kant reconoce tres formas de idealismo: - $\mathbf{j}-$ el idealismo material dogmático, que considera que la "existencia" de los objetos en el espacio no es susceptible de prueba alguna (y que convierte a los objetos en el espacio en mera "apariencia»); - ii- el idealismo material problemático (Descartes), y - iii-el idealismo formal o transcendental - la doctrina que sostiene la $C R p$ - que afirma que «todo cuanto es intuido en el espacio o en el tiempo, todos los objetos de una experiencia posible para nosotros, no son otra cosa que fenómenos, c.d. meras representaciones, que, tal y como son representadas, como seres extensos o como series de cambios, no tienen una existencia que se sostenga a si misma fuera de nuestros pensamientos". El idealismo transcendental expresa la necesaria constitución finita del ser para que haya Razón - tal y como esta se expone en las tres Críticas-.

2. Al idealismo transcendental se opone el «realismo transcendental», que considera (u) la renlidad externa es absolusa (y por tanto es consecuente con el idealismo material -i-). Lo que interesa a Kant ante todo es la modalidad «metalisica» de esta forma de realismo, a saber, aqueIla que afirma la absoluta diversidad del "sujeto" respecto de lo externo (esto es, la posibilidad de la "sustancia" en sentido racionalista. y por ende la negación de la finitud del conocimiento, que es la piedra de toque de la Critica). Pues bien, es en la oposición a esta forma de realismo donde deben leerse las referencias de Kont a Descartes asi como, en general, la reorganización de todos los textos entre la primera y la segunda edición de la $C R p$. [En la segunda edición se producen fundamentalmente las siguientes modificaciones: dos adiciones —unos parigrafos en la Estética y la Refutación del idealismo en la Analitica-y dos cambios de secciones completas - la deducción de las categorias, en la Analítica, y los Paralogismos, en la Dialéctica-. Todas estas modificaciones tienen que leerse de forma unitaria].

3. La primera referencia a Descartes aparece en el cuarto Paralogismo - de la modalidid- de la primera edición. La argumentación de Ḱant se dirige contra pretendida "mediatez" de la percepción externa (consecuencia de la "inmediatez" del "ser pensante en general»), mostrando que la realidad del contenido de las representaciones extermas es insepirable de la realidad de la representación misma ('paradoja del sentido externo'), o lo que es igual, que se trata de una idealidad "finita". [Léase: "idealidad" por cuanto pertenece a la constitución del sujeto de conocimiento. y "finita” por cuanto signilica un siempre estar "en relación” con algo distinto del sujeto].

Este paralogismo es una especie de "refutación" del realismo transcendental, que consiste en mostrar que el espacio es un modo de representación, esto es, ideal. En este sentido el idealismo de Descartes, que problematiza to "externo" al sacar las consecuencias de tomar su realidad como efectivamente absoluta, sirve a este propósito de "idealización" de nutestras representaciones. 
4. En la segunda edición se trata, en cambio, de refutar el idealismo de Descartes. Lo que ahora le intertsa a Kant es distinguir la modalidad del cogito respecto de la experiencia posible. El cogito cartesiano no es más que la mera conciencia de la existencia de un sujeto y no es "experiencia" ni por ende conocimiento; decir que "conocemos" nuestra existencia significa decir que somos conscientes de nosotros mismos cabe la experiencia. Esto supone dos cosas: primero, que es necesaria la presencia de intuición; $y$, segundo, que la intuición interna no basta para procurar la determinación de la existencia (ni tampoco en general cualquier forma de conocimiento). Sólo puedo tener conciencia de mi existencia de ser pensante en tanto que ser corpóreo.

4.1. La crítica que esboza en los tres primeros paralogismos en $A$ apunta a este hecho: a que el «texto» de la psicologia racional, el "Yo pienso", no puede str objeto de conocimiento (no es posible una psicologia racional como "doctrina"), ya que no hay intuición. Esto significa —dada la esencial dualidad que comporta la sintesis- que no hay categorias esquematizadas (sino "categorías puras») ni tampoco intuición. La presunta "predicación" de estas no es más que una mera «exposición lógica» de la apercepción (esto es, a falta de tiempo no se puede hablar de un "uso»).

4.2. Ahora bien, Kant obtiene un rendimiento positivo de esta imposibilidad. Y esto en un doble respecto. Por lo que hace al conocimiento (uso teórico de razón), Kant introduce en B la "paradoja del sentido interno", a saber, el hecho de que el sentido interno nos "presenta" a la conciencia como un fenómeno - y no-como-cosa-en-si-misma-; donde la "limitación" radica en la naturaleza finita de todo objeto de experiencia a que nos referimos antes, esto es, en la necesaria copertenencia de espacio a la determinación empirica (conocimiento). Todo conocimiento de nosotros mismos (a través del sentido interno) implica necesariamente «afección», esto es, requiere la "presencia" de espacio (en sentido empirico). Donde esta remisión es justamente la que permite distinguir la experiencia interna de la apercepción; el interés de Kant no es otro que "diferenciar cuidadosamente» $-\mathrm{y}$ con cllo poner a salvo la distinción entre- la determinación cmpirica y la determinación o sintesis pura - llámese "autoafección» [de acucrdo con el anadido de B en la Estética] o "sintesis transcendental de la imaginación» [añadido de B en la Analitica]-. [Queda sin tratar la cuestión de la finitud de la apercepción transcendental -espontaneidad teórica-, también conectada con cierta "exterioridad"].

4.3. Por lo que hace al respecto príctico, la "imposibilidad" de una «doctrina” del alma recibe el nombre de disciplina. En la primera edición Kant insiste en la "vaciedad" de las categorias puras y por tanto en la distinción entre "conocimiento" y "exposición lógica". En B Kant señala que la proposición «Yo pienso» expresa una "intuición", esto es, afección, pero con independencia de la forma del sentido interno, distinción que debe leerse en el mismo horizonte que la que hemos señalado en la Analitica, a saber, en la linea de salvaguardar la espontaneidad del sujeto. Sólo que aquí Kant distingue entre "existencia" en el tiempo -conocimiento del yo como objeto de los sentidos-, y "existencia" moral - "sentimiento" del sujeto afectado por su espontaneidad práctica-. [Dejamos igualmente sin tratar la cuestión de la finitud de esta fàcultad y por qué es la cosmologia el lugar en el que puede emerger esa determinación].

5. El diálogo de Kant con Descartes constituye, pues, una suerte de "traza" del movimiento de profundización en la finitud del conocimiento que acontece entre las dos ediciones de la $C R p$ y que hemos liamado "revisión" del idealismo transcendental. 